\title{
O.S.P.
}

L'orientation scolaire et professionnelle

$33 / 1 \mid 2004$

Varia

\section{P. Coslin. Les conduites à risque à l'adolescence}

Paris : Armand Colin

\section{Pascal Mallet}

\section{(2) OpenEdition}

Journals

Édition électronique

URL : https://journals.openedition.org/osp/2266

DOI : 10.4000/osp.2266

ISSN : 2104-3795

Éditeur

Institut national d'étude du travail et d'orientation professionnelle (INETOP)

Édition imprimée

Date de publication : 15 mars 2004

Pagination : 173-174

ISSN : 0249-6739

Référence électronique

Pascal Mallet, «P. Coslin. Les conduites à risque à l'adolescence », L'orientation scolaire et professionnelle [En ligne], 33/1 | 2004, mis en ligne le 22 octobre 2009, consulté le 21 septembre 2021. URL : http:// journals.openedition.org/osp/2266; DOI : https://doi.org/10.4000/osp.2266

Ce document a été généré automatiquement le 21 septembre 2021

(c) Tous droits réservés 


\section{P. Coslin. Les conduites à risque à} l'adolescence

Paris : Armand Colin

Pascal Mallet 


\section{RÉFÉRENCE}

Paris : Armand Colin

1 Les conduites à risque sont fréquemment évoquées lorsqu'il est question de l'adolescence : toxicomanie, sexualité ou alimentation imprudentes, accidents de la circulation ou liés à la pratique d'un sport, fugue, délinquance, comportement suicidaire... Dans Les conduites à risque à l'adolescence, Pierre Coslin présente une vaste recension de ces conduites, précédée dans le premier chapitre par une analyse anthropologique de leur signification, d'une manière générale et plus spécialement à cette époque du développement. Chacun des douze autres chapitres porte sur une catégorie de risque spécifique («les jeunes et l'alcool», "grossesse et I.V.G.», «incivilités et violences scolaires», etc.). L'auteur fait état de données épidémiologiques relatives à la population française et analyse les ressorts psychologiques et sociologiques des conduites considérées. Il se fonde sur des études récentes, notamment celles réalisées en France lorsqu'il en existe, et recourt à des modèles explicatifs variés, tels que la psychanalyse, la sociologie, la psychologie cognitive ou la psychobiologie. Grâce à cette riche somme d'informations le lecteur sera en mesure de distinguer, dans l'association "adolescence-conduites à risque ", ce qui correspond à des faits avérés et ce qui relève d'une vision dramatisée - mais hélas ordinaire - de cette période de la vie. Dans un domaine d'actualité où les écrits à sensations l'emportent sur l'analyse rationnelle, l'ouvrage contribue utilement à inverser la tendance. Il s'adresse aux étudiants en sciences humaines et tout particulièrement en psychologie, aux professionnels de l'adolescence et aux responsables institutionnels concernés par cette population. 